\title{
360 Degree Feedback Appraisals- An Innovative Approach of Performance Management System
}

\author{
Dr. Satyawan Baroda ${ }^{1}$, Chhavi Sharma ${ }^{2}$, Jyoti Kandpal Bhatt ${ }^{2}$ \\ ${ }^{1}$ Reader, Department of I.M.S.A.R, M.D. University, Rohtak, Haryana, India \\ ${ }^{2}$ Assistant Professor, Department of business Management, SRCEM, Palwal, Haryana.
}

\section{ABSTRACT}

360-degree feedback systems are typically introduced as part of individual or organisational development activities. However, 360-degree feedback is increasingly used as an integral part of performance appraisal, relating to administrative decisions such as promotions, terminations and pay (Fletcher \& Baldry, 1999; Fletcher, 2001). There has been vigorous debate among practitioners and academics concerning the role of 360-degree feedback in the HR function (Bracken et al., 1997; Garavan et al., 1997; Handley, 2001). The use of such systems for developmental purposes only is based on the argument that their application for other uses (e.g. linking them to pay or performance appraisal) lessens the impact and outcome from the process (Alimo-Metcalfe, 1998). "The concept of 360 degree feedback makes a lot of sense and, if used well, should have a great deal to offer. It seems to suit the move towards the less hierarchical, more flexiblystructured and knowledge based organisations of the future" Professor Clive Fletcher Goldsmiths College, University of London, in today's changing and volatile world organisations are continually looking for ways to improve performance, and satisfy the demands of all stakeholders. Achieving this almost inevitably involves change, which then becomes the pivotal dynamic for success.
Keywords: Performance, Performance management system, 360 degree feedback, Performance appraisal.

\section{INTRODUCTION}

For an organisation to evolve the people working within it will have to adapt; and for this to be successful, they first of all need to know what it is about the way they are currently performing that needs to change. This is where 360 degree feedback is playing a growing role in organisations through its ability to provide structured, indepth information about current performance and what will be required of an individual in the future to enable detailed and relevant development plans to be formulated. Historically, employees received feedback only from their direct supervisor. With flattened structures and the need to respond quickly to customer demand, 360-degree feedback ("360 feedback") was introduced to equip employees with the information needed to deal with change and to leverage individual talent to meet organizational goals. Today, many companies fully customize the 360 degree feedback process to the specific competencies and values required to meet their goals, often creating multiple sets of competencies to ensure relevancy to the business. Some companies have gone further and linked the process to performance appraisal and succession planning.

Organizational leaders clearly have many choices when selecting performance evaluation and development tools. One tool that has gained popularity and has become a 
growing trend in Corporate America in recent years is the 360 degree performance review.

EXHIBIT 1-Types of out comes in an organization

\begin{tabular}{|c|l|c|}
\hline 1 & $\begin{array}{l}\text { The employee's job } \\
\text { performance improved as a } \\
\text { result of 360 feedback }\end{array}$ & $\mathbf{3 . 3}$ \\
\hline 2 & $\begin{array}{l}360 \text { feedback provided a } \\
\text { competitive advantage to the } \\
\text { organization }\end{array}$ & $\mathbf{2 . 7}$ \\
\hline 3 & $\begin{array}{l}360 \text { feedback helped the } \\
\text { organization strive to achieve its } \\
\text { major goals }\end{array}$ & $\mathbf{2 . 9}$ \\
\hline 4 & $\begin{array}{l}360 \text { feedback increased } \\
\text { profitability in the organization }\end{array}$ & $\mathbf{2 . 3}$ \\
\hline 5 & $\begin{array}{l}\text { The 360 feedback process was } \\
\text { worth the resources committed }\end{array}$ & $\mathbf{3 . 8}$ \\
\hline 6 & $\begin{array}{l}\text { 360 feedback was beneficial to } \\
\text { the organization }\end{array}$ & $\mathbf{3 . 6}$ \\
\hline
\end{tabular}

This popularity is based on the perceptions of organizational leader's that 360 degree reviews establish a culture for continuous learning and provide more global feedback for employees, which leads to improved performance. According to Human Resource Consultant, William M. Mercer, forty percent of American companies used 360 degree feedback in 1995; by 2000 this number had jumped to sixty-five percent. In 2002, $90 \%$ of Fortune 500 companies were using a 360 degree performance review process. 360 degree reviews are intended to give an employee the opportunity to understand and remedy any friction points or issues that may exist between themselves and the rest of the organization. Friction points often times include issues in the areas of interpersonal relationships, teamwork, communication and management style. The true ability of a 360 degree review to remedy these types of issues is in question. Clearly the 360 degree feedback process is popular. The perceived benefits of implementing such a program will only be realized if it is utilized in the right organizational climate with the appropriate expectations for success. In the wrong environment, without the presence or proper training of feedback coaches and raters, the results can be detrimental. Organizations should carefully weigh all the costs, including process related as well as the cost of behavioral outcomes. Success of such a program is predicated on implementing and sustaining long term behavioral change and development. Careful consideration should be given to the design of the process as well as to the implementation in order for the process to drive performance behaviors and performance outcomes.

A major concern of organizations centres on the performance of employees. Performance refers to what an employee does or doesn't do on the job. Employee performance includes for example, quantity of output and quality of output. Performance management integrates management of organizational and employee performance. Baron and Armstrong (1998) emphasized the strategic and integrated nature of performance management by stressing that it focuses on increasing the effectiveness of organizations by improving the performance of employee and by developing individual and team capabilities. Performance management as a process recognize that, in a globally competitive business environment it is essential that the efforts of every employee of the firm are focused on helping the firm achieve its strategic goal. Performance management is a critical component for achieving and maintaining effectiveness of individuals and organizations. Performance management system is the entiregamut of activities from performance planning to performance enhancement. Presence of such a system in an organization provides opportunities to individuals and teams in the organization receive feedback about their performance. 


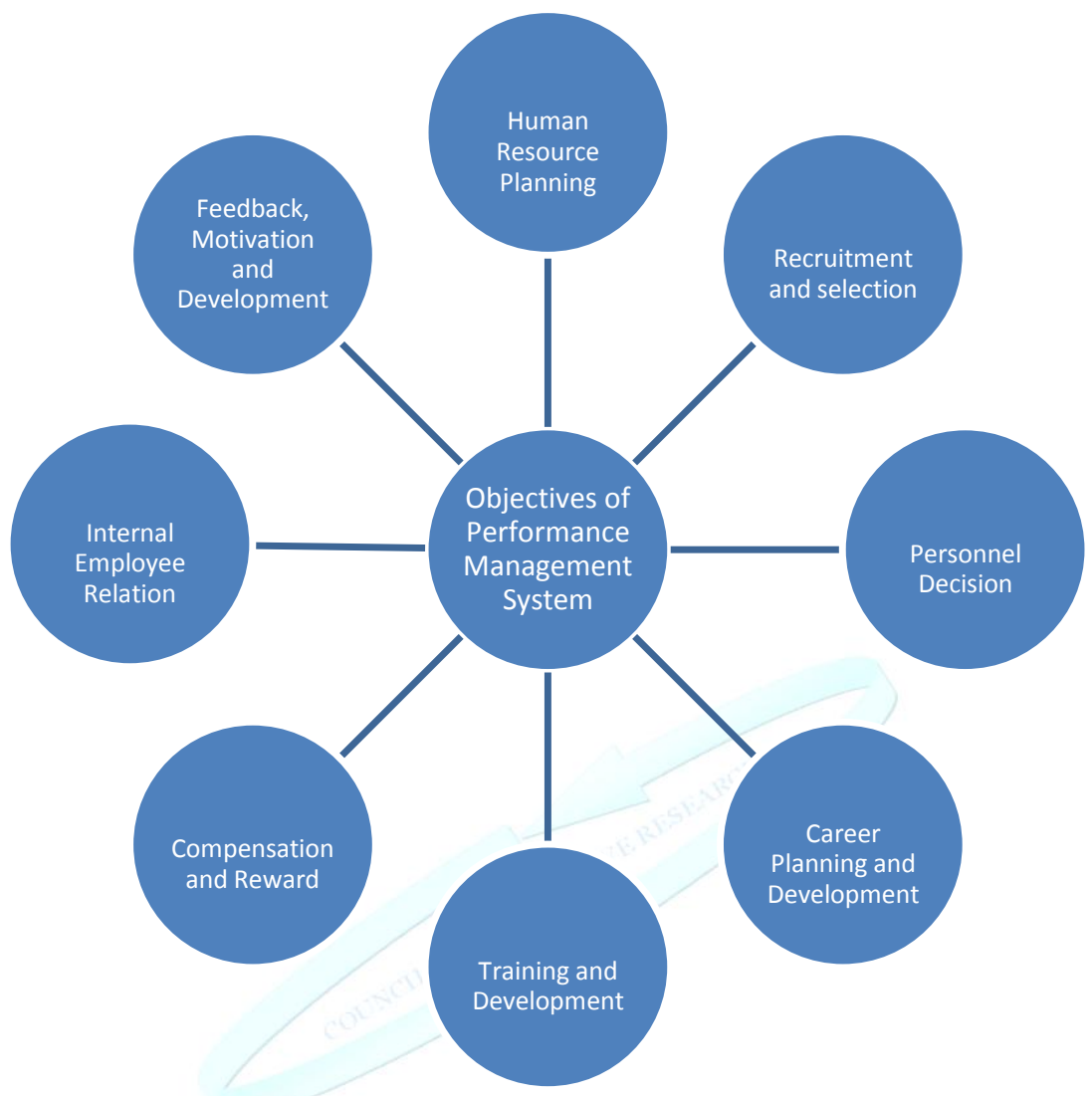

Fig-1 Uses and Objectives of Performance Management System

\section{WHAT IS 360 DEGREE FEEDBACK?}

Traditionally, performance review processes have involved an employee receiving feedback from one source, the supervisor. As illustrated below, 360 degree feedback involves an employee receiving feedback from a variety of sources, which might include staff reporting to the position colleagues and clients. This information is used to identify strengths and development needs.

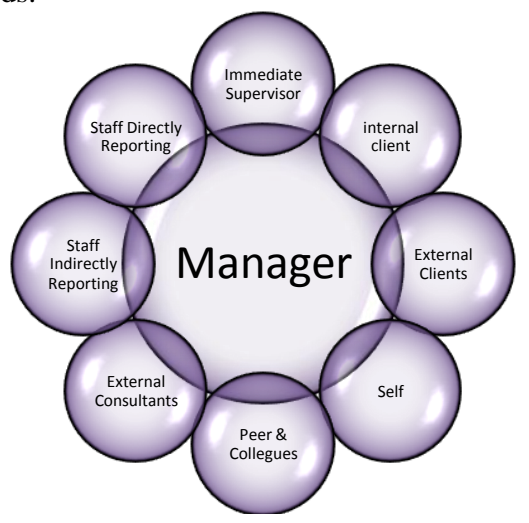




\section{CORPORATE EXAMPLES OF PERFORMANCE MANAGEMENT SYSTEM}

Larsen and Toubro, the engineering major, has developed a competency matrix which lists 73 competencies to measure performance and assess the developmental needs of its employees. These competencies vary across managerial levels. Each competency has associated knowledge, skills and attributes. Individual employees are appraised on the listed competencies. Based on this assessment, functional managerial and behavioural skill gaps are identified. The competency matrix is linked to business strategy on one hand and training needs on the other. The development policies are driven by the strategic needs of the organization ensuring that the process of reskilling is focused.

HUGHES ESCORTS, the subsidiary of U.S. headquarter telecom company, HUGHES, uses a competency based performance enhancement model. Each position in the organization is defined in terms of 23 key competencies. These competencies are categorizes into four groups -

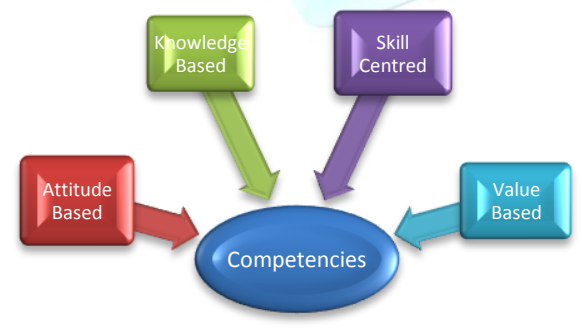

\section{Source:}

http://themanagementor.com/kuniverse/kmail ers_universe/hr_kmailers/perf_best.htm, acces sed on 26 September 2006

These competencies are used to measure gaps. Relevant training input are given based on competency gaps identified. The objective is to maximize productivity as well as to help individual employee understand their professional status with respect to these competencies.

Many firms have expanded the idea of upward and peer feedback into 360 degree feedback. Here ratings are collected all around an employee, from supervisors, subordinates, peer and internal or external customers ${ }^{\mathbf{1}}$.

Employers generally use the feedback for development rather than for pay increases. Most 360- degree feedback systems contain several common features. Appropriate parties- peers, supervisors, subordinates and customers, for instance- complete surveys on an individual. The survey often include item such as "Return phone calls promptly", "Listen well" or "Keeps me informed". Computerized \& Web-based system compiles this feedback in to individualized reports, just for the rates. They then meet with their own supervisors sometimes with their subordinates and share the information they feel is pertinent for self-improvement. Some doubt the practicality of 360-degree feedback. Employees usually do these reviews anonymously. So those with an ax to grind can misuse them. A "Dilbert" cartoon, announcing that evaluations by co-workers will help decide raises, has one character asking "if my co-workers got small raises, won't there be more available in the budget for $\mathrm{me}^{2}$.

Thus, 360-degree appraisal is the subject of considerable debate. One study found significant correlations between

- 360-Degree ratings

- Conventional performance ratings ${ }^{3}$

Another study concluded that multi-source feedback leads to "generally small" performance improvements on subsequent ratings 4 .

However anchoring 360-degree appraisals with behavioral competencies improves the rating reliability; in one study, the competency-based 360-degree assessments were strongly predictive of how the managers 
performed in a subsequent assessment centre ${ }^{5}$.

The consulting form Watson Wyatt, found that companies using 360-degree type feedback have lower market value, perhaps due to the methods complications ${ }^{6}$.

All in all, the findings suggest that firms should carefully assess the potential costs of the program, focus any feedback very clearly on concrete goals, carefully train the people that are giving and receiving the feedback and not rely solely on 360-degree feedback. And the company should make sure that the feedback is productive, unblased and development oriented.

Like a compass, 360-degree feedback systems act to help managers gain a panoramic view of the impact they are having in the work landscape. While the 360degree method has gained popularity over the past decade among corporate leader for employee developmental purposes, the feedback can also serve as a listening device for managers to provide information about how well they are communicating. What's more, when employees are allowed to give input about how their manager's style is being perceived empowering results take place $^{7}$.

\section{A RECENTLY POPULAR INNOVATION PERFORMANCE MANAGEMENT}

The use of 360 degree appraisal which provides a multidirectional measurement scope for employee performance. Thus, an employee might receive feedback from several sources, including:

- Downward feedback from the supervisor.

- Upward feedback from subordinates.

- Lateral feedback from peers.

- Inward feedback from oneself.

- Customer feedback from both internal and external customers ${ }^{8}$.
360 degree feedback should be congruent with the organisation's strategy and should measure important target behaviours. As one recent article relayed thus point: "what gets measured drives behaviour". Even when 360 degree feedback ratings are used strictly for developmental purposes, individuals will tend to modify behaviours.

In ways to receive more positive ratings. Therefore, it is extremely important that 360 degree surveys reflect those behaviours that the organization values most highly. The innovative aspect of the companies approach to the 360- degree system is that the company decided to base the system on the internet \& its own intranet. Zan independent contractor, E group development the system and handles the collation and analysis of the feedback information ${ }^{9}$

E Group chose a 75-item survey called LEAPS, which measures seven dimensions of leadership for the 360-degree instrument. The instrument was loaded on a web site so that all raters can pull up the information \& complete the appraisal in app. 20 minutes. After completing the appraisal, they simply submit the results via e-mail to E-Group to process. Because the system is encrypted the company is able to provide greater confidentiality and anonymity for the raters than with the previous paper and pencil system. In addition to the LEAPS items, the company included a fairly large set of other items to assess manager's technical competency and their contributions to the business. E-Group was able to provide appraisal profile for the managers within 3 days after the last of the evaluators' e mailed their input for the manager.

In addition, the profile of actual ratings for each manager from E Group also includes utives. An ideal leadership profile developed by otis executives. By comparison of his or her actual ratings with the ideal profile. Managers can identify areas for future development. Otis elevator chose to use the system only for developmental purposes, although recently it began to consider other purposes for the system ${ }^{10}$. 


\section{REASONS FOR ADOPTING 360 DEGREE FEEDBACK}

A key purpose driving the present use of 360 degree feedback is the desire to further management or leadership development. Providing feedback to managers about how they are viewed by direct subordinate, peers and customers/clients should prompt behaviour change. Many managers have not received as much honest feedback as is necessary for an accurate self perception. When anonymous feedback solicited from others is compared with the managers self evaluations, the manager may from a more realistic picture of his or her strengths and weaknesses identified were previously unknown to the manager, especially when such change is encouraged and supported by the organization. Other potential benefits of 360 degree initiatives are targeted ultimately toward organizational change and improvement. These initiatives reflect resources dependence theory, which views organizational change as a rational response to environmental pressure for change or strategic adaptation ${ }^{11}$.

A second alternative reason for the proliferation of 360 degree feedback is the desire to expand formal appraisal processes by making such feedback evaluative, thereby linking it directly with a managers or employee's performance appraisal. Our most recent experiences suggest that there are pressures to make 360 feedbacks evaluative because companies want to get their money's worth.

In theory, the use of 360 feedbacks for evaluative purposes seems logical. An individual held directly accountable for ratings received will be more motivated to take action to make improvement based on the feedback. Unfortunately, problems exist that may negate the possible benefits of 360 degree feedback if it is made evaluative.

Employees may rebel and try to sabotage the program. For e.g. in the case of upward feedback, implicit and even explicit deals may be struck with subordinates to give high ratings in exchange for high ratings. Such maneuvering is less likely when the feedback is provided strictly for developmental purposes. Research has demonstrated that when ratings become evaluative rather than purely developmental, some rater (up to $35 \%$ ) change their ratings ${ }^{\mathbf{1 2}}$.

The company asked employees after they had provided upward ratings whether they would have altered the ratings if they knew they would be used as part of their managers for performance evaluations. Their findings suggested that some individual would raise \& some would even lower ratings if they were to be used for evaluation. A rating should be used for appraisal purposes only when the rater is committed to the goals of the organization, rather than merely to their own personal goals. This is often not the case, as the rater is primarily concerned with his or her own short term needs. For e.g. A subordinate may only provide high upward feedback rating to a manager who maintains the status quo, even though the individual\& the organization could use a high degree of challenge.

This suggests another caution regarding ratings be careful what you measure if a manager's 360 ratings depend on creating a positive or even relaxed climate, these factors may actually detract from work directly geared toward bottom line result. For e.g. Customer may the entire manager away from the office frequently or necessitate many horse on the phone, thus making the manager less available to employees. If this customeroriented behaviour is not part of the criteria measured and availability to subordinates is part of the criteria, customer-oriented behaviour will diminish over time and be replaced by more frequent interaction with employees. Yes relationship with employees may improve, but at what cost?
6. MULTISOURCE FEEDBACK AND 360 DEGREE APPRAISALS 
Many firms have combined the different sources of performance appraisal into a 'multi source' appraisal \& feedback system, popularly called the 360 degree appraisal. One of the main purposes served by the 360 appraisal system is to obtain information about the employee's performance in multiple roles and from different perspectives. Amway, a direct selling organization practices a group appraisal system where a manager is appraised by his management team as well as customers.

For example -At lupin laboratories self evaluation \& colleague evaluation is used to assess several characteristics such as ability to recall, concept retebaining feedback from all angles-subordinate, peers, customers, supervisors, etc. feedback from multiple sources may reinforce \& support the feedback provided from the supervisor, thus making it harder to discount negative feedback from the supervisor as one person's feedback that is perhaps biased.

The traditional top-down appraisal system appears to be increasingly inconsistent with recent developments is management thought $\&$ practice. For e.g. as organization eliminate boundaries vertically across hierarchies, horizontally across departments and organizationally between firms \& their customers, 'the boundary-less appraisal' that is 360 degree appraisal has emerged as a more viable alternative to traditional appraisals. Several firms such as shell, Exxon Mobil, IBM, AT \& T, Levi Strauss, Fedex etc have started using 360 degree appraisal and feedback systems. The AV Birla Group, Gillette, and Ballaspur industries have 360 degree feedback system for senior level managers. It is expected that 360 degree system will result in more comprehensive picture of an employee's performance \& developmental needs and since ratings are anonymous, a more honest evaluation is possible. The 360 degree appraisal approach is more appropriate for developmental purposes than for evaluative purpose. Feedback from multiple sources helps employees in self development. However,
360 degree appraisals have also begun to be used for making evaluative or administrative decisions. For instance, an employee's incentives may be linked to customer feedback. Reliance industries ltd., Crompton greaves, Godrej soaps, Wipro \& Infosys all use 360 degree feedback primarily for self correction \& fact finding purposes.

\section{GENERAL GUIDELINES TO IMPLEMENT 360 DEGREE SYSTEM IN AN ORGANIZATION}

Some firms that seeks to implement the 360 degree system should follow certain general guidelines such as-

1. Determine the potential cost of the programme.

2. Focus feedback on specific goals.

3. Train employees giving \& receiving feedback.

4. Ensure that the feedback is productive, unbiased and development oriented.

\section{FACTORS IMPACTING 360 DEGREE APPRAISAL}

Some factors may impact the acceptability of 360 degree appraisals by both the appraiser $\&$ the appraise. These are

a) Organizational Cynicism- when employees in an organization hold the common belief that potentially fixable problems cannot be resolved due to factors beyond the control of the employees, it results in organizational Cynicism. Both the appraiser \& appraise may nurture cynicism about the 360 degree appraisal system. To manage cynicism, it is important to first implement 360 degree as a pilot project \& allow organization members to experience the process.

b) Purpose of appraisal- employee who are evaluated by peers and managers who are evaluated by subordinate, all prefer that feedback from 360 degree 
appraisals should be used solely for development \& feedback. Those who appraise may find the 360 degree appraisal system more acceptable when ratings are used for evaluative purpose, but the appraise may not find this acceptable.

c) Anonymity- this becomes an issue in 360 degree appraisals. With traditional appraisals, anonymity is not an issue. The supervisor evaluates and shows the written appraisal to the subordinate only to file it in personnel records. 360 degree appraisal on the other hand, incorporates upward appraisals that are appraisals of employees by those who are lower than them in the organizational hierarchy.

d) Acceptability- Acceptability of 360 degree appraisals is also affected by the extent to which work is designed around teams. Traditionally, performance appraisals are designed around the jobs that are not related or dependent on other jobs or tasks. Since co-workers are at the same organizational level, with in the same group, they are likely to have closer interpersonal relationships and to be in direct competition for organizational rewards.

e) Competency of appraisers- Appraises may find it difficult to accept ratings or feedback when perceive that the appraiser does not have the competence to appraise \& hence any ratings provided by them will be perceived as biased or unfair. Appraise may perceive to appraiser to be lacking in competence when-

- The appraiser is not familiar with the work of the appraise, as in the case of external customers who may not be aware of various workrelated pressures of the appraise

- Appraises are unwilling to be appraised by those who they believe cannot themselves perform the task.

\section{POTENTIAL PROBLEMS OF 360 DEGREE APPRAISAL FEEDBACK}

1. Considerable anxiety for the employee when appraisals are negative. The employee may get a feeling that everyone is 'Ganging Up' against him/her.

2. Customers, subordinates and peers can also be biased. Their lack of accountability can further.

3. Anonymity and breach of privacy can become a major issue. Since several employees are involved in 360 degree appraisal systems, it is likely that evaluators may discuss an employee's appraisals and violate privacy.

4. Peers may deliberately evaluate a manager lower than he/she should be in order to increase their own chances of promotion. This tendency is enhanced because the 360 degree appraisal system is anonymous.

10. 360 DEGREE APPRAISAL -SOME SUGGESTIONS TO MAXIMIZE BENEFITS AND MINIMIZE RISK

1. Provide training to employees to enhance self-awareness. This minimizes inflation in ratings \& also results in more accurate self ratings.

2. Provide orientation to all employees about the implementation of the 360 degree appraisal process.

3. Assess degree of organizational cynicism among employees prior to implementing 360 degree appraisal.

4. Follow-up negative feedback with encouragement $\&$ coaching.

5. Integrated 360 degree feedback with other training and development efforts. Providing feedback to suggest changes, without providing training or assistance will result in lower motivation on the part of recipients of the feedback. 
6. Institutionalize 360 degree appraisal as part of the organizational culture.

Source: Atwater, Waldman and Brett 2002.

Putting it all together:360 degree appraisal Many companies are combining various sources of performance appraisal information to create multi rater or 360 degree- appraisal $\&$ feedback systems. Jobs are multifaceted and different people see different things. 360degree feedback intended to provide employees with as accurate a view of their performance appraisal as possible by getting input from all angles: supervisors, peers, subordinates, customer \& the like. An estimated $25 \%$ of U.S employers and more than $90 \%$ of fortune 1000 companies have implemented some form of 360- degree feedback system for career development. Performance appraisal or both because the system combines more information than a typical performance appraisal, it can become administratively complex. For that reason, organization have recently begun using employee management software (EPM) to compile and aggregate the information. Approximately $20 \%$ use the web or other software for their performance management system, another $33 \%$ plan to do so in the near future $^{13}$.

For e.g. performance plus and competency plus developed by exceed a Chicago company, allow managers and employees to develop performance plan, goals and objectives and then track their progress overtime. Managers can see all of an employee's goals and action steps on a single screen and self -appraisal and multiple-raters reviews can be combined into 360-degree format. After rating an employee's performance on each goal, raters can provide summary comments in 3 categories: victories and accomplishments, setbacks and frustrations and general comments. To ensure security, a user id and password are required and all the data are captwod \& saved in the employees history file. Other type of EPM software can calculate and manage and financial rewards based on how well employees perform as well as identify their performance gaps and manage their education, certification and training ${ }^{14}$.

When Intel established a 360-degree system the company observed the following safeguards to ensure its maximum quality and acceptance:

a) Assure anonymity- make certain that no employee ever knows how any evaluation team member responded.

b) Make respondents accountablesupervisors, should discuss each evaluation-team member's input, letting each member know whether he or she used the rating scales appropriately. Whether his or her responses were reliable and how other participants rated the employees.

c) Prevent "gaming of the system-some individuals may try to help or hurt an employee by giving either too high or too low an evaluation.

d) Use statistical procedures- use weighted average or other quantitative approaches to combining evaluations.

e) Identify \& quantify biases- check for prejudices or preferences related to age, gender, ethnicity or other group factors ${ }^{15}$.

\section{THE FUTURE OF 360- DEGREE FEEDBACK}

The use of 360-degree feedback is becoming increasingly widespread. In the US, more than $90 \%$ of Fortune 1000 companies use some form of multi-source assessment system for at least developmental feedback. In Australia, increasing use is being made of some form of multi-rater feedback.

360-degree feedback systems are seen as a catalyst for increasing organisational performance and efficiency as feedback from others is considered a highly powerful motivator for behavioural change. With continual innovations in 360-degree processes and software technology, systems 
will be created which is more users friendly, more widely available and more fair, accurate and valid. 360-degree feedback will continue to become a better process for collecting information and applying it. Intelligence will therefore be integrated into 360-degree systems in order to make them faster, easier and better. Thus, 360-degree systems will not only provide important feedback to individuals but also suggest better ways to improve performance.

\section{CASE STUDY - TACT}

TACT is a foster care and adoption services charity. TACT is a national organisation with an annual turnover of c. $£ 14 \mathrm{~m}, 105$ full-time equivalent staff and working agreements with around 300 foster carers. Daniella Black, HR Manager, was responsible for introducing 360 degree feedback in 2004. At this stage, a paper-based system was adopted. Daniella and her colleagues defined a set of competencies for managers and a set for staff. They invited staff to suggest 15-20 people (peers, managers, more junior staff, local authority contacts and foster carers) to give feedback on their performance. From these 15-20 people, the HR team then chose around eight people from whom to seek feedback. HR was responsible for all aspects of coordination: selecting feedback persons, dispatching forms, monitoring, receiving forms and summarising responses.

TACT ran this system for two years running, but there were several disadvantages. The first was the sheer administrative volume for the HR team! In addition, there was some staff mistrust about the confidentiality of the process and managers were not totally 'bought in'. As a result, in 2007, TACT introduced a new 360 feedback scheme, this time using software and engaging an external consultant to assist them. They revised their competencies, taking into account staff views. The current system still involves staff nominating a number of individuals, with $\mathrm{HR}$ selecting a smaller number, to whom they send an electronic invitation to give feedback. The feedback is on a numerical rating scale, but with the opportunity to give comments as well. Individuals who give feedback do so anonymously via the software. Once all feedback is received, reports are generated using the software. The reports include graphical, narrative and data table reports. Daniella and her team have worked with the external consultant to customise the reports to the needs of TACT. The 360 feedback reports are integrated into the appraisal process. There is a section in the appraisal which prompts the manager and employee to discuss and record feedback from the 360 process. Managers have been trained on the 360 feedback system.

\section{Benefits of the system}

Daniella feels it is difficult to evaluate the 360 degree process in a totally objective way, since organisational change often comes about due to a number of factors.

However, she does perceive the following benefits:

- Reduction of the 'blind areas' Danielle feels that 360 feedbacks at TACT has definitely enabled staff to become more self-aware of how they come across to others - a really valuable development tool.

- More effective management of performance Managers have found that the 360 feedback helps them substantiate to staff both learning areas and areas of performance which is already effective.

- Greater ownership of learning and self-development amongst the workforce Daniella said that staff have started to take more responsibility for their own development, because 360 degree feedback requires everyone to really think about how they are working and how they can improve.

- Improvement in behaviour from some individuals Some individuals who were negative or disruptive in their behaviours to other staff have made positive changes for the better. 
Daniella attributes these changes mainly to the 360 scheme.

- Organisational benefits From an organisational perspective, 360 feedback has: helped to communicate and reinforce organisational culture and values; helped improve customer service; and helped identify learning and development needs.

\section{Drawbacks}

- Lack of internet access One disadvantage of the online system is that many foster carers do not have access to the internet. As a result TACT is looking to introduce a paper-based feedback system for this group of individuals only.

- $\quad$ Time required Daniella says that 360 degree feedback is still quite timeconsuming. As a Result of this, TACT now has a rolling programme of appraisals, which are linked to the date each employee completed his/her probation, rather than all appraisals being undertaken at a set time each year. One option in the futur might be to collect 360 feedback on a two-

\section{Next steps} yearly, rather than annual, basis.

- Number of respondents In the future, the plan is to limit the number of respondents to six, in order to make the process more manageable.

- Increased requirement for coaching One unanticipated need arising from the introduction of 360 feedback was for coaching. Coaching has been arranged for a number of individuals, to help them develop in response to feedback from the 360 degree feedback.

- Additional training A next step will be to provide additional training to managers on how best to feedback the results of the 360 process. In addition, training will be arranged for staff on how to use and interpret their 360 reports, as well on how to receive feedback

Further differentiation of competencies

TACT currently have two sets of competencies - one for managers and one for staff. They are contemplating whether, in the future, they might further differentiate, so that, for example, they have different sets of competencies for administrative staff and for social work staff.

\section{Evaluation}

TACT is keen to evaluate the effectiveness of their 360 feedback system further and is in the process of considering appropriate ways to do so. TACT has benchmarked internally areas and placement numbers and linked this to the 360 competency ratings. The 360 feedback system has given TACT the opportunity to address performance of individuals in a constructive way and therefore help improve organisational performance.

\section{The competencies used}

TACT has kindly agreed to share their competencies. They are reproduced below.

\section{Commitment}

- Takes work responsibilities seriously and makes every effort to do a good job.

- Is prepared to adapt to changing circumstances and to help others when the situation requires

\section{Behaviour associated with effective} performance

- Works hard to get the job done.

- Is punctual and reliable in coming to work and attending meetings.

- Is prepared to be flexible and accommodating.

- Speak highly of TACT to outside parties.

- Helps others when they are under pressure.

- Put in extra effort when the situation requires

\section{Problem Solving}

- Behaviour associated with effective performance. 
- Maintain a calm, organised and objective approach when faced with a problem.

- Increase his / her understanding of problems through discussion with others.

- Quickly and accurately analyse all information relating to a problem.

- Check information or assumptions and not accept things at 'face value'.

- Identify the underlying causes of complex or difficult problems.

- Identify wider issues and trends, and anticipate future requirements.

\section{Working with People}

- Encourages people to use their judgement and experience.

- Treats people fairly and builds a positive work environment.

- Behaviour associated with effective performance.

- Treat other people in a way that makes working life enjoyable.

- Make fair and unbiased judgments about people's performance.

- Encourage people to take personal responsibility for key tasks and activities.

- Explain to people how their work contributes to overall performance.

- Praise people for their contribution and encourage them to continue.

- Take steps to eliminate personal criticism or abusive behaviour at work.

\section{Focusing on Results}

- Demonstrates personal drive and initiative with a clear focus on the standards and objectives that need to be achieved.

- Behaviour associated with effective performance Maintain a clear focus on the objectives and standards that must be achieved.

- Demonstrate the personal drive and resilience to overcome problems.
- Take the initiative in developing new, more effective ways of doing things.

- Keep people aware of time-scales and the progress made in achieving objectives.

- Cope well with conflicting priorities and pressure, remaining positive and focused.

- Demonstrate flexibility when faced with an unexpected change of plans.

\section{Client Focus}

- Builds and sustains long-term relationships with internal and / or external clients.

- Focuses on identifying and meeting client needs in the most effective way.

- Behaviour associated with effective performance.

- Build relationships and establish rapport quickly with clients.

- Ensure needs are met within the structure of TACT Standards.

- Monitor and act on client feedback.

- Follow through until the client is satisfied.

- Tailor his / her approach to meet the needs of clients.

- Deliver on promises to clients: 'gets the job done 'Professional Behaviour.

- Dependable, reliable and accountable for own behaviour.

- Acts within professional, legal and ethical boundaries and guidelines.

Behaviour associated with effective performance

- Accept responsibility for his / her own decisions and actions.

- Keep appropriate people informed when things don't go as planned.

- Takes own share of responsibility for resolving problems.

- Demonstrate accountability; can be trusted to do a good job.

- Avoid publicly denigrating or undermining other managers/colleagues. 
- Act professionally and ethically.

- Behaves in an anti-discriminatory manner towards others.

\section{Team Work}

- Cooperates and collaborates with colleagues inside and outside own area to achieve shared goals.

- Contributes actively to help create effective partnerships which meet organisational objectives.

- Behaviour associated with effective performance.

- Treat all people fairly and respectfully.

- Appear approachable, listens well and makes time for colleagues.

- Collaborate with and learn from others.

- Build rapport and trusting relationships with colleagues.

- Encourage the involvement of colleagues and helps to build team spirit.

- Promote the sharing of information within the team.

- Communication and Influence.

- Conveys information clearly, accurately and succinctly and adjusts to the audience's needs and requirements.

- Has credibility and impact and uses a range of effective interpersonal skills to persuade others to adopt a particular position and / or take action.

- Behaviour associated with effective performance.

- Communicate clearly and succinctly.

- Adapt his / her communication style to suit topic, audience and situation.

- Aware of his / her non verbal behaviour and its impact on others.

- Easily gains agreement from others to a particular course of action.

- Demonstrate credibility when stating a position.
- Deliver information in an engaging way.

\section{REFERENCES}

1. "360-Degree Feedback on the Rise, Survey finds" BNA Bulletin to Management, January 23, 1997, p.31.

2. Carol Hymowitz, "Do 360- Degree Job Reviews by Colleagues Promote Honesty or Insults?"p. B1.

3. Terry Bechr et al, 'Evaluation of 360-degree feedback rating: relationships with each other \& with performance 7 selection predictors, "Journal of organizational Behaviour 22, no.7 (November 2001), pp.775-778.

4. James Smither et al, 'Does Performance Improve Following Multi-Score feedback? A Theoretical Model Meta Analysis, and Review of Empirical Findings,'

Personnel psychology 58, (2005): 33-36.

5. Christine Hagan, et al, "Predicting Assessment Centre Performance with 360-Degree, Top Down, and Customer-Based Competency Assessments," Human Resource Management, Fall 2006, Vol.45, no. 3, pp. 357-390.

6. Brouce Pfau and Ira Kay, "Does a 360-degree feedback negatively affect the company performance?" HR Magazine, June 2002, pp. 5559. Scott Wimer, "the dark side of 360-degree feedback," training and development, september 2002, pp. 37-42.

7. Adapted from Alan Bailey (March $15,2005)$, "How to square the circle on 360-degree feedback," Personnel today, p.17; and Bryan R.Fisher (August 2004), "Listen to 
what's Really Going On,"

Supervision, pp.9-11.

8. L.R.Gomez-Mejia, D.B.Balkin and

R.L.Cardy, Managing Human

Resources, $2^{\text {nd }}$ ed. (Upper Saddle

River, N.J: Prentice Hall, 1998).

9. I bid.

10. Ulrich, D. \& Barney, J. 1984. Perspectives in organization: resource dependence, efficiency and population. Academy of management review. 9: 471481.360 degree feedback as part of performance appraisal.

11. M. \& Smither, J. 1995. Can multi source feedback change perceptions of goal accomplishment, self evaluations \& performance related outcomes? Theory- based applications and directions for research. Personnel Psychology, 48: 803-839 UPS tested the potential of using 360 ratings for evaluation.

12. Pfau,Kay,Nowak and Ghorpade, 'does 360 degree feedback negatively affect company performance?" 54-59; Periperl, "Getting 360-degree feedback right," 142-47.

13. Ref. David W. Bracken, Lynn Summer and John Fleenor, "high tech 360," Training and Development 52, no. 8 (August 1998): 42-45.

14. “ Performance Appraisal ," HR Magazine 47 no.10 (October 2002): 146; Frank E. Kuzmits, Arthur J.Adams, Lyle Sussman \& Louis E. Raho, "360-feedback in Health care management: A field study," the health care manager 23, no.321 (October-December 2004): 321-29. 